the Maastricht Meeting would not have been what it turned out to be. I owe him a lot.

Although the first main congress can be considered a success, the scientific quality of these congresses needs improvement. At the next main congress, to be held in Prague in 1999, symposia on timely topics will be organized and internationally renowned scientists will be invited to participate in these symposia. The Executive Committee of FEPS is doing its utmost to raise funds to create a financial basis for this activity.

The workshops on timely topics will be accessible only to a limited number of scientists - currently we are thinking of about 60 participants - and should be a stimulating environment for scientific discussions between young scientists, for example, post-docs, and renowned scientists. This can be achieved by a format of relatively short introductions and extensive informal discussions. In addition, the organization of symposia on specific topics, among others, in collaboration with Springer Verlag, is foreseen. The topics and the potential organizers of workshops and symposia can be proposed by Member Societies, or by individual members of these societies, to the Meeting Committee of FEPS, which is chaired by Dr. Peter Bie from Copenhagen, Denmark. The organization of workshops and symposia under the auspices of FEPS requires approval of its Executive Committee.

Through the coordinating activities of our Meeting Committee, proposals for four workshops have been submitted already to the European Science Foundation (ESF) for funding. These are:

- Renal microcirculation, regulatory and pathophysiologic processes (Chairperson: Daniel Casellas, Montpellier, France).

- Renal renin-angiotensin system, molecular and integrative aspects (Chairperson: Ole Skøtt, Odense, Denmark).

These workshops have been submitted under the ESF theme: Regulation of kidney function. Molecular and integrative aspects.

- Factors and indices of human adaptation (Chairperson: Maria Kopp, Budapest, Hungary)
- Psychosocial and physical job factors in breakdown of human adaptation (Chairperson: Töres Theorell, Stockholm, Sweden).

These workshops have been submitted under the ISF theme: Breakdown of human adaptation. Psychophysiological aspects.

Besides sponsoring through the ESF, the Executive Committee of FEPS is looking into the possibility of financially supporting workshops and symposia through other sources. In a stable situation we are aiming at 1-2 workshops and/or symposia per year. Hopefully this situation can be reached before the turn of the century.

In summary, the baby has started walking, but it needs a lot of effort to guide it safely through adolescence to adulthood. The help of all member societies is needed to accomplish this. Robert S. Reneman, Maastricht June 1996

President, FEPS

Chairman, Organizing Committee

First FEPS Congress, Maastricht

September 9-12, 1995

\title{
Announcement
}

\section{To the Constituent National Physiological Societies of the Federation of European Physiological Societies (FEPS)}

The space made available to FEPS in the European Journal of Physiology - Pflügers Archiv is intended to provide readers with information about FEPS and its Constituent Societies. The Executive Committee of FEPS therefore would like to receive short communications from its Constituent Societies, for example on the history and the organization of physiology, the training facilities on physiology for undergraduates and graduates and specific problems physiology is facing in their countries.

These 1-2 page communication can be sent to the Secretary-General of FEPS Prof. Dr. Christian Bauer, Physiologisches Institut, Winterthurerstraße 190, CH-8075 Zürich, Switzerland.

Robert S. Reneman, Maastricht, President, FEPS 